\title{
Open-Source for Educational Materials Making Textbooks Cheaper and Better
}

\author{
Ed Diener ${ }^{*}$, Carol Diener ${ }^{\dagger}$ and Robert Biswas-Diener ${ }^{*}$ \\ "University of Virginia \\ †University of Illinois \\ *Noba, robert@nobaproject.com
}

\begin{abstract}
Editors' Commentary
Aside from being expensive, traditional textbooks are also rigidly structured, environmentally unfriendly, and unnecessarily long. As a result, although most open textbook projects attempt to produce an openly licensed version of a resource that most faculty will find familiar, authors Ed Diener, Carol Diener, and Robert Biswas-Diener-all affiliated with Noba-set out to do something different. The model that they have created, with leading scholars authoring over 100 brief modules (supported with high quality ancillary resources) that faculty may customize using a user-friendly interface, represents a new and innovative model for open educators in other disciplines. In this chapter the authors discuss their rationale for the Noba project, describe some of its successes and challenges, and share their hopes for the future of open education.
\end{abstract}

When we reflected on our combined decades working as instructors in academia, we saw strengths in the educational system in which we worked; but also shortcomings. One of the biggest problems that emerged across our tenure as instructors was the rising cost of a college education. There are many reasons

How to cite this book chapter:

Diener, E, Diener, C and Biswas-Diener, R. 2017. Open-Source for Educational Materials Making Textbooks Cheaper and Better. In: Jhangiani, R S and Biswas-Diener, R. (eds.) Open: The Philosophy and Practices that are Revolutionizing Education and Science. Pp. 209-217. London: Ubiquity Press. DOI: https://doi.org/10.5334/bbc.p. License: CC-BY 4.0 
why education has become more expensive but one factor that stood out to us was the cost to students of textbooks. We landed on this factor becauseunlike cost of living or tuition-it is one that faculty have a direct influence upon. According to The Enterprise Institute ${ }^{1}$ textbook prices have increased more than 800 per cent since 1978. By contrast, the Consumer Price Index-a measure of variation in the price of common retail goods-has only risen $250 \%$ in that same period. The consequences of this are predictable: A US PIRG sur$v^{2} y^{2}$ of more than 2,000 students from 156 campuses revealed that $65 \%$ of the students surveyed indicated that they had decided against buying a required course text because of the expense. Over $90 \%$ do so knowing that it could adversely affect their grades. Students Surveys reveal that many students never buy the textbook for a class, and just try to get along without it. In this chapter, we will discuss the problematic landscape of textbooks and relate the story of how we came to address these problems through Noba.

\section{Traditional Textbooks}

Textbook prices are kept high by several means:

1. New Editions. First, publishers ask authors to update their books frequently, meaning that older and used books cannot be assigned by professors because they are viewed as 'out of date.' Whether the scholarship in various fields that undergraduates need to learn has actually changed enough to warrant continual revisions of textbooks is, in our view, doubtful. One clear example of this can be seen in the instance of the release of the latest Diagnostic and Statistical Manual of Mental Disorders. ${ }^{3}$ Following the publication of the DSM-5 many textbook publishers rushed new introductory psychology books to market that promised special DSM-5 updates. It is not entirely clear, however, that the taxonomic structure or diagnostic criteria for clinical professionals found in the DSM are an important enough influence on introductory undergraduate and high school psychology that a revised book is warranted. While experts might argue over the scale of changes between the DSM-IV and DSM-5 (were they large or small?) there were very few changes that would affect how basic material was introduced to general psychology students. It is possible that the new editions of DSM-5 compatible textbooks reflect a market demand but it is also possible that this is an illustration of the profit driven edition cycle common in academic publishing.

2. Non-traditional economic model. Another factor that keeps textbooks high is that professors select the books, but students pay for them. In our experience this means that instructors really are not price sensitive, and this allows much higher prices than if professors or universities were paying for the books. In a traditional economic model supply and competition would 
serve to reduce costs. The clearest corollary with the economic model of textbooks - at least in the United States - is prescription medicine. In the US doctors are the ones who often choose the medication but patients are the ones who pay for them. Not surprisingly, prescription medications, according to Consumer Reports, ${ }^{4}$ are also rising at an alarming rate (1 in 10 medications rose in price by more than 100 per cent over a one year period from 2013-2014).

3. Size. The third factor that makes textbooks prices so lofty is that they try to cover a huge amount of material in an attempt to cover any and every topic that a professor might want. This results in very, very large texts that cover much more material than any student could possibly learn in a single course. So-called brief textbooks are a notable market solution to this problem and, in themselves, a recognition that traditional texts may be too long.

Beyond the issue of expense, we noticed a number of additional problems with traditional textbooks. For one thing, they use a lot of paper, and many students are increasingly comfortable with digital materials, including texts. Although surveys commonly point to the conclusion that the vast majority of students continue to use print textbooks many also find that as many as $30 \%$ prefer digital texts ${ }^{5}$ and $80 \%$ find e-books helpful in completing assignments and test preparation. ${ }^{6}$ Second, textbooks present certain material and present it in a fixed order. Thus, instructors who want to customize their course face a challenge in organizing the materials for students. For decades, instructors have tailored course content to reflect their own preferences and students have endured syllabi that suggest reading 'Chapter 2' and then 'Chapters 4 and 9' and then 'Chapter 6.' Digital texts could easily solve this problem. We also heard professors say that they would like more on certain topics, and coverage of topics that are not in the text they choose. The so-called standard canon-the topics found in many introductory psychology books-appears to preference some historically accepted topics such as hypnosis, while overlooking others such as the current replication crisis, the academic publication process, and knowledge emotions. Again, computer based textbooks offer a solution because they allow professors to add and subtract material from their textbooks. Finally, digital textbooks also allow added features such as embedded learning assignments, videos, interactive simulations and hyperlinks that have the potential for increasing student learning while they read the text.

One final issue related to the cost of traditional textbooks is that many scholarships will cover tuition, but not textbooks. Thus, the students are on their own, and a shocking number of students report not buying the books for all of their classes. This puts needy students at a disadvantage compared to more affluent ones.

Although we see the problems with textbooks we-the authors of this chapter-do not consider ourselves above them. We have assigned traditional textbooks. Instructors buy into the current model of expensive texts sold by 
commercial publishers for several reasons. One reason is that many of the textbooks are well-written and of reasonably high quality. They contain interesting side bars and high quality graphics. They are well edited. Their popularity is also based on other factors. For instance, professors find it convenient and easy to use commercial texts because they come with a variety of teaching aids such as instructors' manuals, test banks, and PowerPoint presentations. Last, traditional textbooks are popular for the same reason that some brands of beer are: namely, they are a commercial product at the tip of a large marketing spear. Sales reps send emails, free samples, and drop by the office to answer questions. Some publishers of traditional texts supply faculty with travel grants and other 'development money'. Somewhere between the high cost, the inflexible structure, and the lack of student input there is a clear problem in need of a solution.

\section{The Advantages of Digital Textbooks}

There are several suggestions alluded to in the previous section. All of them are based on the properties of the digital medium. It might sound strange to focus so heavily on digital in a book about open resources but the truth is 'digital' and 'open' go hand in glove. In open education circles advocates often talk about an 'abundance model' rather than the traditional 'scarcity model'. It is the advent of digital technology that allows us to easily create, modify and share materials at an unpresented rate. The proliferation of access to the internet has dovetailed with the gaining traction of the open movement. It is the reason why open exists today and not back when scribes were scratching cuneiform on clay tablets.

Based on the comments above, here is a summary of the advantages of digital (and open-source) texts:

1. Less expensive. Publication costs do not include paper, ink, packaging or shipping. Revisions can be made more easily without rewriting the entire book, and the costs of shipping and printing are negligible. Therefore the notion of 'revised editions' can be supplanted by 'revisions as necessary'. Even if students choose to print out a hard-copy of their open textbook, or use a print on demand service the costs are much lower than traditional texts. For example, Noba's textbook 'Discover Psychology 2.0' currently retails for less than 15 US dollars plus shipping. Admittedly, it is a softcover, black and white book, but we regularly receive student feedback suggesting this is an acceptable trade.

2. Easier on the environment. Digital texts do not require physical manufacture or shipping.

3. Foreign access. It is much easier to access materials, especially in poor nations where costs are a serious concern. Many economically developing nations have invested in internet infrastructure. 
4. Individualization. Instructors can select only the modules he or she wants to cover in a course, and can add or subtract material from chapters. An extension of the idea of individualization is localization. The open format allows instructors around the world to modify content so that it is more relevant and relatable to their students.

5. Alternative chapters can be made available. Digital textbooks can use alternate forms of the same material. For example, a text might offer an overview chapter on 'The Brain and Nervous System' but also offer more specialized units on 'Neurons' and 'The Biochemistry of Love.'

6. Active learning. The digital format offers a variety of methods for increasing in the moment learning including "mouse overs" (e.g., definitions pop up on screen), 'adaptive learning' (tests embedded in the chapter that track individual student performance and adapt to it), and hyperlinks to related videos and readings.

7. Accessibility. The open format has fewer restrictions regarding printing, copy and pasting, sharing, and re-sizing - to name a few-which means that these resources support assistive learning for students who need accommodation.

\section{The Noba Model}

Two of us (ED and CD) decided to fund Noba because of the problems we saw with the current textbook model. We felt comfortable focusing our efforts exclusively on psychology because it is considered a high enrollment course with a large potential for student savings. Our initial idea was to have experts for each topic in psychology write chapters on their respective areas. For example, we received our chapter on 'Eyewitness testimony' from Elizabeth Loftus and our chapter on 'Evolutionary theories in psychology' from David Buss. By focusing exclusively on our own area of expertise (psychology), and by investing in a model that emphasizes expert created content we have largely been able to side step some of the common skepticism of quality faced by many OERs. In fact, we have developed a sophisticated quality assurance program that includes:

1. Expert created content.

2. Editorial review.

3. Peer review.

4. Student review.

5. International review.

6. Accessibility review.

7. Empirical review.

We also opted for a modular approach in which instructors could drag and drop each chapter in which they were interested into a unique course textbook 
and assign it only to their own students. We created 100 different modules ranging from 'research methods' to 'creativity' to 'mood disorders' covering all corners of psychology. The modular approach means that Noba materials can be used either as a collated textbook or as supplemental reading. Of course, all of these materials are Creative Commons licensed and it was our strong intention to make them free for all students.

To generate enthusiasm for Noba we also directed money toward faculty and students in the form of grants and awards, none of which were contingent on using Noba. On the faculty side we awarded grants for the review of our materials and for experimenting with new digital capabilities. For example, because textbooks can now be individualized it is possible that instructors could assign core content and each individual student could select additional chapters that represented his or her own unique interest. It is possible that having 30 unique textbooks in a class of 30 students is a management nightmare for instructors. It is equally possible that this method is an unprecedented means of engaging students and increasing interest. We'll have to wait until the data are in to see. On the student side we awarded 10 thousand dollars each of two years for the creation of short videos that would become a permanent part of Noba catalog.

It is here, perhaps, that we are most proud of Noba. Earlier digital and open source textbooks were simply electronic versions of traditional textbooks. Because the Noba system is built around modules it is changing the way we think about what a textbook is, what it can do, and how it can impact learning.

Then, an interesting thing happened. Instructors did not flock to our site. Many seemed unmoved by the free price tag. Some refused to mention Noba to their local psychology clubs. Others criticized our experts as being 'biased.' We heard first hand reports that sales reps from large publishers were warning faculty members away from open source materials such as Noba, suggesting that they are low quality. It was surprising and unsettling. Ultimately, we interviewed instructors and learned a simple truth: they are dedicated and passionate teachers who are often overworked and who have little reserve energy to evaluate a new text, let alone create new lectures and tests if they adopt one.

Based on this insight we shifted our priorities from textbook creation to instructor support. We collaborated with a large team of experts in both psychology and instructional design to create high quality test banks, instructor manuals and PowerPoint presentations. We created a print on demand version of our textbooks that sells for less than US\$15. We partnered with Cerego, an adaptive learning technology company, to embed each of our modules with an adaptive quiz function. We revised many modules so that they employed simpler language and more international examples. We created a blog of practical teaching ideas and offer essays on a variety of teaching topics ranging from teaching large classes to teaching biological psychology. We gave additional grants to instructors to pilot a review of our materials and create rubrics for evaluating Noba that can be used by individual instructors and departments 
both. We ensured that our materials were accessible to those with visual impairments and other disabilities. In essence, we tried to think of every small concern or headache an instructor might face in deciding whether to adopt Noba and deal with it. And, if it was not clear before, it's all free to all of our users.

The result of our efforts is-three years in-visible. We are being officially adopted at two and four year institutions such as Northwest Vista College (a 2-year institution using Noba with approximately 1,500 students a year), West Virginia University (approximately 3,000 students a year), and East Georgia State University (an institution that reports US\$114 per student in savings. We are being recommended by our colleagues and are receiving higher satisfaction and engagement ratings from our users. Most importantly, we have saved students-using a conservative estimate-more than two million dollars in textbook fees.

We also track out impact qualitatively through feedback be receive from instructors and departments that use Noba. Here are two such examples that highlight both the financial and pedagogic benefits:

'Teaching with Noba gives me freedom as an instructor. It gives me freedom to assign as little or as much to my students as I would like. It gives me freedom to supplement my teaching rather than overshadow it. It gives me the freedom of knowing my students (some of the poorest in the nation) are not falling behind because they are waiting on financial aid to come through.' -Raechel Soicher, Linn-Benton Community College

'I am thrilled that we have such a wonderful resource for our students. We have over 3,000 Introduction to Psychology students each year at WVU and you can imagine how much money this saves our students. Even after the semester is in its 2nd week we have students asking where to buy the textbook. It's nice to remind them that the resource is free.' Constance Toffle, West Virginia University

\section{The Future of Open Education}

The cost of college education has been spiraling upward, and textbooks are one part of this trend. Textbooks are much more expensive than they need to be, and open-source texts are one solution to the problem. Furthermore, the digital format has the potential to radically transform the way that texts are used as instructional aids and we are only beginning to scratch the surface of this potential. In the future, instructors will better be able to modify the actual text, the examples, and the featured research contained within modules. To some degree, that very concept is anathema to academic culture. Many professors place a premium on their intellectual property and value their own authorial voice. The notion that someone else might tinker with that can-admittedly-be unsettling. Rather than simply dismissing the idea of open-source collaboration 
future educators must engage in a discussion about how this process can occur while still preserving the scientific rigor we all prize so highly.

It is our hope that in the near future we will see a sea change in the attitudes of individuals and institutions regarding open materials. We would like to see a day where high quality open materials are the standard and students must opt out to purchase additional resources. Boards of trustees, university administration, alumni groups, student groups, and even legislatures can bring pressure to bear to use cheaper textbook alternatives. Many are fearful of seeming to tread on academic freedom, but selecting from among the less expensive opensource textbooks does not truly limit in any way the material they cover in their courses-and this is what academic freedom is.

\section{Notes}

1 Weissmann, 2013.

2 Senack, 2014.

${ }^{3}$ American Psychiatric Association, 2013.

${ }^{4}$ Consumer Reports, 2015.

${ }^{5}$ Bolkan, 2015.

${ }^{6}$ Falc, 2013.

${ }^{7}$ Affordable Learning Georgia, 2016.

\section{References}

Affordable Learning Georgia. (2016). Textbook transformation grants: Round one projects gallery fall 2014 - spring 2015. Retrieved from http://www. affordablelearninggeorgia.org/site/round1

American Psychiatric Association. (2013). Diagnostic and statistical manual of mental disorders (5th ed.). Washington, DC: Author.

Bolkan, J. (2015). Survey: Most students prefer traditional texts over e-books. Retrieved from https://campustechnology.com/articles/2015/09/01/surveymost-students-prefer-traditional-texts-over-ebooks.aspx

Consumer Reports. (2015). Are you paying more for your Rx meds? A consumer reports' poll shows one-third of Americans hit by high drug prices. Retrieved from http://www.consumerreports.org/cro/news/2015/08/areyou-paying-more-for-your-meds/index.htm

Falc, E. O. (2013). An assessment of college students' attitudes towards using an online e-textbook. Interdisciplinary Journal of E-Learning and Learning Objects, 9, 1-12.

Senack, E. (2014). Fixing the broken textbook market: How students respond to high textbook costs and demand alternatives. Retrieved from http:// 
uspirg.org/sites/pirg/files/reports/NATIONAL\%20Fixing\%20Broken $\% 20$ Textbooks\%20Report1.pdf

Weissmann, J. (2013, January 3). Why are college textbooks so absurdly expensive? The Atlantic. Retrieved from http://www.theatlantic.com/ business/archive/2013/01/why-are-college-textbooks-so-absurdly-expensive/266801/ 
